\title{
ПРАКТИЧЕСКИЕ РЕКОМЕНДАЦИИ ПО ЛЕЧЕНИЮ ХРОНИЧЕСКОГО БОЛЕВОГО СИНДРОМА У ОНКОЛОГИЧЕСКИХ БОЛЬНЫХ
}

Коллектив авторов: Когония Л.М., Новиков Г.А., Орлова Р.В., Сидоров А.В. DOI: $10.18027 / 2224-5057-2020-10-3 s 2-49$

Ключевые слова: хронический болевой синдром, анальгетики, опиоиды, нестероидные противовоспалительные препараты, адъювантные средства

\section{1. ОПРЕДЕЛЕНИЕ}

Международная ассоциация по изучению боли (IASP) дает боли следующее определение: «Боль представляет собой неприятное сенсорное и эмоциональное переживание, связанное с имеющимся или возможным повреждением тканей. Боль всегда субъективна. Каждый человек воспринимает ее через переживания, связанные с получением какого-либо повреждения в ранние годы его жизни. Боль - это телесное ощущение, но она также представляет собой всегда неприятное и поэтому эмоциональное переживание».

Хроническая боль определяется IASP как боль, сохраняющаяся или рецидивирующая на протяжении более трех месяцев. Хронический болевой синдром часто приводит к ограничению повседневной или трудовой деятельности и тесно связан с такими коморбидными расстройствами как тревога, депрессия и суицидальные тенденции.

Традиционно используемый 3-месячный интервал времени от момента возникновения болевых ощущений в достаточной степени условен и больше подходит для боли неонкологического генеза. Главным отличием хронической боли от острой является не временной фактор, а качественно иные нейрофизиологические, психофизиологические и клинические соотношения. Важной характеристикой хронической боли является ее продолжительность сверх периода нормального заживления тканей. В связи с этим постоянная, или персистирующая, боль, связанная со злокачественным новообразованием, может расцениваться как изначально хроническая.

Выяснение патогенеза, определение типа боли, ее динамики, построение четкого плана лечебных мероприятий и их активный контроль - обязательные компоненты эффективной терапии ХБС.

Цитирование: Когония Л.М., Новиков Г.А., Орлова Р.В., Сидоров А.В. Практические рекомендации по лечению хронического болевого синдрома у онкологических больных. Злокачественные опухоли: Практические рекомендации RUSSCO \#3s2, 2020 (том 10).49 


\section{2. ЭТИОЛОГИЯ И ПАТОГЕНЕЗ БОЛЕВОГО СИНДРОМА У ОНКОЛОГИЧЕСКИХ БОЛЬНЫХ}

Выделяют следующие основные причины болевых синдромов у онкологических больных:

- Боль, вызванная самой опухолью (поражение костей, мягких тканей, кожи, внутренних органов, окклюзия сосудов и др.)

- Боль при осложнениях опухолевого процесса (патологический перелом, некроз, изъязвление, воспаление, инфицирование тканей и органов, тромбозы)

- Боль при паранеопластических синдромах (артро-, нейро, миопатии)

- Боль как следствие астенизации (пролежни, трофические язвы, запор)

- Боль, обусловленная противоопухолевым лечением:

- при осложнениях хирургического лечения рака (фантомная боль, боли при спайках, рубцах, отеках);

- при осложнениях химиотерапии (мукозиты, полинейропатия, генерализованная миалгия, астенический некроз, артралгии);

- при реакциях и осложнениях лучевой терапии (поражение кожи и слизистых оболочек, костей, фиброз, неврит, плексит, миелопатия и др.).

\section{3. ДИАГНОСТИКА}

\section{1. Жалобы и анамнез}

Рекомендуется тщательный сбор жалоб и анамнеза у пациента с целью выявления факторов, которые могут повлиять на выбор тактики лечения:

- первые жалобы, связанные с возникновением боли;

- длительность болевого синдрома;

- максимальная интенсивность боли за последние 24 часа;

- общие проявления болезни: слабость, потливость, похудание, гипертермии.

\section{2. Физикальное обследование}

Рекомендуется выполнять тщательный физикальный осмотр для уточнения локализации боли, включающий осмотр всех кожных покровов и видимых слизистых, пальпацию всех доступных групп лимфатических узлов, щитовидной железы, молочных желез, органов брюшной полости, пальцевое ректальное исследование, осмотр гинекологом (женщины), исследование наружных половых органов, пальпация яичек (мужчины). 


\section{3. Оценка интенсивности боли}

\subsection{1. Шкала вербальных оценок (ШВО)}

По шкале вербальных оценок (измеряется в баллах при совместном решении врача и пациента):

0 - боли нет;

1 - слабая боль;

2 - умеренная боль;

3 - сильная боль;

4 - нестерпимая боль.

\subsection{2. Визуально-аналоговая шкала}

По визуально-аналоговой шкале от 0 до $100 \%$. Пациенту предлагают отметить на неградуированной линии длиной 10 см точку, которая соответствует интенсивности боли. Левая граница линии соответствует определению «боли нет», правая - «нестерпимая боль». С помощью линейки измеряется расстояние от «боли нет» до точки, отмеченной пациентом.

Как правило, для проведения методики используется обратная (неградуированная) сторона 10-сантиметровой бумажной, картонной или пластмассовой линейки (см. рис. 1).

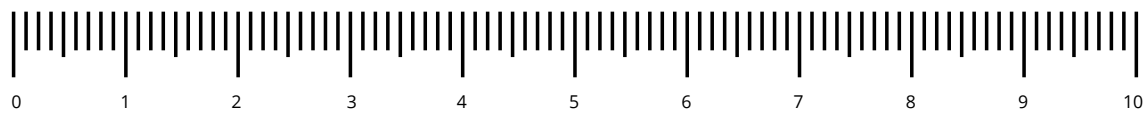

Рисунок 1. Визуально-аналоговая шкала для оценки интенсивности боли.

Степень интенсивности боли по ВАШ:

- Нет боли - 0 ,

- Слабая - до 40 \% (до 4 см),

- Умеренная - 40-70\% (4-7 см),

- Сильная - более $70 \%$ (более 7 см),

- Нестерпимая - 100\% (10 см).

К преимуществам данной шкалы относятся ее простота и удобство. Недостатком является одномерность ВАШ - оценка лишь интенсивности боли. Эмоциональная составляющая болевого синдрома вносит существенные погрешности в результаты, полученные с помощью ВАШ. Другими недостатками теста является невозможность его выполнения в устной форме или по телефону, необходимость наличия расходных материалов и затруднительность применения у лиц с когнитивными нарушениями. В последнем случае оценка интенсивности боли проводится аналогично педиатрической практике - на основе поведенческих реакций, выражения 
лица, положения и движений тела, мышечного напряжения, вербализации и вокализации, а также возможности отвлечь или утешить пациента.

\subsection{3. Нумерологическая оценочная шкала (НОШ)}

Нумерологическая оценочная шкала, иначе - числовая рейтинговая шкала, является цифровой версией ВАШ. Она представляет собой горизонтальную линию, длиной 10 см, с расположенными на ней цифрами от 0 до 10, где 0 - «отсутствие боли», 10 - «нестерпимая боль». Пациента просят выбрать число от 0 до 10, соответствующее выраженности его болевых ощущений. НОШ может применяться как в устной форме (в т. ч. по телефону), так и в графическом виде, что является преимуществом в сравнении с ВАШ. Однако НОШ также принимает во внимание только один компонент болевого синдрома - его интенсивность и не учитывает всю сложность и особенности природы боли у конкретного пациента (см. рис. 2).

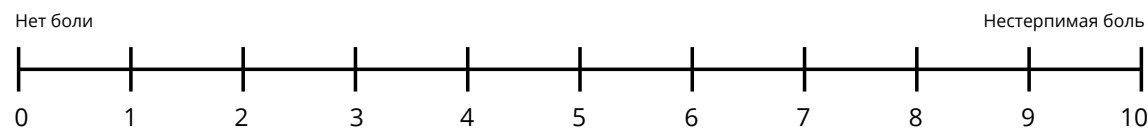

Рисунок 2. Нумерологическая оценочная шкала.

\subsection{4. Оценка физической активности (ФА) больных по пятибалльной шкале ЕСОG (Eastern Cooperative Oncology Group)}

0 - нормальная физическая активность (ФА);

1 - ФА незначительно снижена

2 - ФА умеренно снижена (постельный режим - менее $50 \%$ дневного времени);

3 - ФА значительно снижена (постельный режим - более $50 \%$ дневного времени);

4 - полный постельный режим.

\subsection{5. Оценка качества ночного сна}

- хороший (6-8 4);

- удовлетворительный (4-6 ч);

- плохой (менее 4 ч).

\subsection{6. Оценка эффективности обезболивающей терапии}

- оценка времени начала аналгезии после разовой дозы препарата;

- продолжительность действия разовой дозы препарата;

- расчет разовых и суточных доз основного анальгетика в динамике на этапах терапии;

- расчет суточных доз дополнительных анальгетиков;

- оценка длительности терапии анальгетиком (сут.). 


\subsection{7. Оценка переносимости противоболевой терапии}

- учет ПЭ (побочных эффектов) предшествующей терапии;

- выявление основных ПЭ, связанных с приемом анальгетика: седации, головокружения, тошноты, рвоты, повышенного потоотделения, сухости во рту, головной боли, снижения аппетита, нарушений функций пищеварительного тракта (запоров, диареи), задержки мочи, общей слабости, психических расстройств;

- степень выраженности ПЭ по четырехбалльной шкале:

0 - ПЭ отсутствуют (отличная переносимость);

1 - легкая (хорошая переносимость);

2 - умеренная (удовлетворительная переносимость);

3 - сильная степень выраженности (плохая переносимость).

\subsection{8. Оценка невропатического компонента боли}

Для диагностики невропатического компонента боли применяют опросник DN4 (Neuropathic Pain Diagnostic Questionnaire, pис. 2a).

\section{СОБЕСЕДОВАНИЕ С ПАЦИЕНТОМ}

\begin{tabular}{|c|c|c|}
\hline $\begin{array}{l}\text { Вопрос } 1 \\
\text { Соответствует ли боль, которую испытывает пациент, одному или нескольким из следующих } \\
\text { определений? }\end{array}$ & Да & Нет \\
\hline 1. Ощущение жжения & $\square$ & $\square$ \\
\hline 2. Болезненное ощущение холода & $\square$ & $\square$ \\
\hline 3. Ощущение как от ударов током & $\square$ & $\square$ \\
\hline $\begin{array}{l}\text { Вопрос } 2 \\
\text { Сопровождается ли боль одним или несколькими из следующих симптомов в области ее } \\
\text { локализации? }\end{array}$ & Да & Нет \\
\hline 4. Пощипыванием, ощущением ползания мурашек & $\square$ & $\square$ \\
\hline 5. Покалыванием & $\square$ & $\square$ \\
\hline 6. Онемением & $\square$ & $\square$ \\
\hline 7. Зудом & $\square$ & $\square$ \\
\hline \multicolumn{3}{|l|}{ ОСМОТР ПАЦИЕНТА } \\
\hline $\begin{array}{l}\text { Вопрос } 3 \\
\text { Локализована ли боль в той же области, где осмотр выявляет один или оба следующих } \\
\text { симптома? }\end{array}$ & Да & Нет \\
\hline 8. Пониженная чувствительность к прикосновению & $\square$ & $\square$ \\
\hline 9. Пониженная чувствительность к покалыванию & $\square$ & $\square$ \\
\hline $\begin{array}{l}\text { Вопрос } 4 \\
\text { Можно ли вызвать или усилить боль в области ее локализации? }\end{array}$ & Да & Нет \\
\hline 10. Проведя в этой области кисточкой & $\square$ & $\square$ \\
\hline
\end{tabular}


Сумма баллов (количество ответов «Да»): если сумма составляет 4 и более баллов, это указывает на то, что боль у пациента является нейропатической или имеется нейропатический компонент боли (при смешанных ноцицептивно-нейропатических болевых синдромах).

\subsection{9. Дополнительная диагностика}

- Рекомендуется выполнить компьютерную томографию (КТ) органов грудной клетки, брюшной полости с внутривенным контрастированием.

- КТ или магнитно-резонансную томографию (МРТ) головного мозга с внутривенным контрастированием при подозрении на метастатическое поражение головного мозга.

- Рекомендуется выполнить позитронно-эмиссионную томографию, совмещенную с КТ (ПЭТ-КТ) при подозрении на метастазы по данным КТ или МРТ в случаях, когда их подтверждение принципиально меняет тактику лечения.

- Сцинтиграфия костей с рентгенографией костей в зонах накопления радиофармпрепарата при сканировании.

\section{4. ЛЕЧЕНИЕ}

\section{1. Принципы терапии хронического болевого синдрома}

Эффективная терапия хронической боли - сложная задача, которая требует многостороннего подхода с использованием различных методов и лекарственных средств. Основным, наиболее удобным, в большинстве случаев эффективным и безопасным методом лечения ХБС является фармакотерапия. Фундаментальными ее принципами у онкологических больных, согласно рекомендаций ВОЗ $(1986,1996,2018)$, являются нижеперечисленные.

\subsection{1. Ступенчатый подбор анальгетиков}

Последовательное использование анальгетиков разных групп - от ненаркотических анальгетиков и НПВП до «слабых» и «сильных» опиоидов в соответствии с трехступенчатой «лестницей обезболивания» ВОЗ (рис. 3). Переход на более сильный анальгетик определяется недостаточностью эффекта принимаемого препарата в максимально переносимой дозе и/или развитием нежелательных явлений. Валидационные исследования ступенчатой методики обезболивания ВОЗ демонстрируют ее эффективность у 77-90\% онкологических больных. 


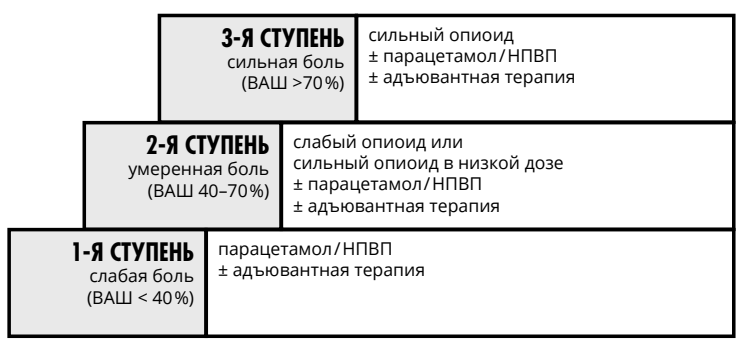

Рисунок 3. «Лестница обезболивания» хронической онкологической боли у взрослых согласно BO3 $(1986,1996,2018)$ с учетом рекомендаций $\operatorname{EAPC~(2012)~и~} \operatorname{ESMO~(2018).~}$

\subsection{2. Индивидуальный подбор доз анальгетиков "по нарастающей»}

Эффективность анальгетиков у одного и того же пациента варьируется. В связи с этим выбор препарата и подбор дозы путем «титрования» должен осуществляться строго индивидуально, с учетом интенсивности боли и переносимости лекарственного средства.

\subsection{3. Приём "по часам", а не "по требованию больного»}

Анальгетик должен вводиться регулярно с целью предотвращения, а не устранения боли после её возникновения. Соответственно, необходимо учитывать период полувыведения и продолжительность действия анальгетика для регулярного приема. Применение анальгетика «по требованию» требует значительно больших доз лекарственных средств и имеет отрицательное психологическое действие. Данный принцип не противоречит применению дополнительных анальгетиков в качестве терапии спасения при прорывной боли. Таким образом, регулярно принимаемые анальгетики (длительного или короткого действия) при необходимости должны быть дополнены средствами быстрого действия для купирования прорывной боли.

\subsection{4. Активное применение адъювантов}

Необходимо учитывать патофизиологическую основу боли (ноцицептивная, нейропатическая) и ее локализацию (висцеральная и костно-суставная и т. п.) и дополнять обезболивающую терапию ко-анальгетиками (антидепрессантами, антиконвульсантами, спазмолитиками, глюкокортикостероидами и т. д.). Данные препараты могут применяться на любой ступени обезболивания.

\subsection{5. Приоритетное использование неинвазивных форм лекарственных препаратов}

Предпочтение должно отдаваться пероральному способу введения анальгетика как наиболее эффективному, простому, удобному и наименее болезненному 
для большинства пациентов. Альтернативой пероральным лекарственным формам являются суппозитории с НПВП и трансдермальные терапевтические системы опиоидов. К инъекционному способу введения анальгетиков для постоянной терапии ХБС следует прибегать в исключительных случаях при невозможности использования неинвазивных лекарственных форм. При этом более предпочтительным является подкожный путь введения; внутривенные инъекции используются только в случае необходимости достижения быстрого эффекта; внутримышечный путь введения в силу болезненности не должен применяться для постоянного обезболивания.

В некоторых случаях (при наличии интенсивного болевого синдрома и недостаточном контроле боли посредством традиционной опиоидной терапии) может рассматриваться эпидуральное или интратекальное введение опиоидов.

\section{2. Интервенционное лечение хронической онкологической боли можно разделить на две категории}

\subsection{1. Нейромодулирующие техники}

К ним можно отнести интратекальное или эпидуральное введение опиоидов или других активных препаратов, а также воздействие специальным образом модулируемого электрического тока на отдельные нервы или нервные стволы. Импульсная радиочастотная абляция позволяет специалисту воздействовать на смешанные нервы, прерывая импульсацию по нему, не затрагивая двигательные порции нервных волокон. Это делает возможным отключение болевой импульсации от определенной зоны на любом уровне - от отдельного нерва до сплетения или чувствительных дорзальных ганглиев спинного мозга на срок до нескольких месяцев;

\subsection{2. Нейродеструктивные техники}

К ним относят полную или частичную деструкцию болепроводящих путей химическим или термическим способом. Наиболее часто в лечении ХБС применяют деструкцию нервов (например, чревного сплетения при опухоли поджелудочной железы и органов брюшной полости, невролиз подчревного сплетения и непарного ганглия - при опухолях малого таза, радиочастотную абляцию ганглия тройничного нерва - при опухолях лица и т. д.).

К недостаткам интервенционного лечения боли следует отнести необходимость участия в лечении специально подготовленных квалифицированных специалистов, дорогостоящего оборудования и длительного мониторинга пациентов в связи с определенными рисками вследствие лечения. Поэтому интервенционные методы лечения хронической онкологической боли должны рассматриваться при недостаточной эффективности рекомендованной «лестницы» ВО3. 
В любом случае решение об использовании интервенционных методов лечения и выборе конкретного метода всегда должно приниматься индивидуально с учетом потенциальной пользы и всех возможных рисков для пациента.

В настоящее время специалисты, занимающиеся лечением болевого синдрома, располагают различными методами, среди которых - фармакотерапия анальгетиками периферического и центрального действия, адъювантные лекарственные средства, использование контролируемой пациентом анальгезии, регионарные методы обезболивания (проводниковые блокады нервных стволов и сплетений, эпидуральная, субарахноидальная, сакральная анестезия, хроническая эпидуральная электростимуляция), консервативные методы денервации (алкоголизация, химическая денервация периферических и центральных нервных структур, радиочастотный нейролизис), хирургические методы (хордотомия, ризотомия, микрохирургические методы), лучевая терапия, чрескожная электростимуляция, иглотерапия.

\section{3. Фармакотерапия хронического болевого синдрома}

Согласно рекомендациям ВОЗ (2018), у взрослых (в т. ч. пожилых лиц) и подростков в качестве стартовой терапии болевого синдрома онкологического генеза следует использовать НПВП, парацетамол и опиоиды, как в виде монотерапии, как и в комбинации, в зависимости от клинической оценки и интенсивности боли, с целью достижения быстрого, эффективного и безопасного контроля боли. При этом сила стартового анальгетика должна соответствовать интенсивности боли у пациента. Таким образом, слабые (неопиоидные) анальгетики (парацетамол, НПВП) не должны назначаться в виде единственной терапии пациенту, страдающему от боли умеренной или сильной интенсивности. При сильных болях терапию можно начинать с назначения парацетамола/НПВП в комбинации с опиоидом (например, пероральным морфином).

Для поддерживающей терапии онкологической боли у взрослых (в т. ч. пожилых лиц) и подростков может использоваться любой опиоид (в виде монотерапии или в комбинации с парацетамолом и/или НПВП), позволяющий достичь устойчивого, эффективного и безопасного обезболивания. Выбор опиоида зависит от состояния пациента и интенсивности боли. Ответ на препараты опиоидов варьируется у разных пациентов. Каждому пациенту требуется тщательный подбор дозы. Правильно подобранная доза опиоида - доза, позволяющая контролировать боль на приемлемом (переносимом) уровне (менее 4 баллов по шкале 0-10).

Зарегистрированные в РФ опиоидные анальгетики, показанные для терапии боли онкологического генеза, представлены в таб. 1 и 2. Как обсуждалось выше, в терапии ХБС предпочтение следует отдавать неинвазивным лекарственных формам. 
Таблица 1. Перечень зарегистрированных в РФ опиоидных анальгетиков в неинвазивных лекарственных формах

\begin{tabular}{|c|c|c|}
\hline $\begin{array}{l}\text { № } \\
\text { п/ா }\end{array}$ & $\begin{array}{l}\text { Международное непатен- } \\
\text { тованное наименование }\end{array}$ & Лекарственная форма \\
\hline 1. & Бупренорфин + налоксон & Таблетки сублингвальные 0,2 мг/0,2 мг ${ }^{1}$ \\
\hline 2. & Морфин & $\begin{array}{l}\text { Таблетки, покрытые пленочной оболочкой } 5 \text { мг, } 10 \text { мг } \\
\text { Раствор для приема внутрь } 2 \text { мг, } 6 \text { мг или } 20 \text { мг/1 мл в ампулах по } 5 \text { мл } \\
\text { Капсулы пролонгированного действия 10, 30, 60, } 100 \text { мг } \\
\text { Таблетки с пролонгированным высвобождением (пролонгированного } \\
\text { действия), покрытые пленочной оболочкой } 10 \text { мг, } 30 \text { мг, } 60 \text { мг, } 100 \text { мг }\end{array}$ \\
\hline 3. & Оксикодон + налоксон & $\begin{array}{l}\text { Таблетки с пролонгированным высвобождением, покрытые пленоч- } \\
\text { ной оболочкой } 5 \text { мг/2,5 мг; } 10 \text { мг/5 мг; } 20 \text { мг/10 мг; } 40 \text { мг/20 мг }\end{array}$ \\
\hline 4. & $\begin{array}{l}\text { Пропионилфенил- } \\
\text { этоксиэтилперидин }\end{array}$ & Таблетки защечные, 20 мг \\
\hline 5. & Тапентадол & $\begin{array}{l}\text { Таблетки, покрытые пленочной оболочкой² } 50 \text { мг, } 75 \text { мг, } 100 \text { мг } \\
\text { Таблетки пролонгированного действия, покрытые пленочной оболоч- } \\
\text { кой, } 50 \text { мг, } 100 \text { мг, } 150 \text { мг, } 200 \text { мг, } 250 \text { мг }\end{array}$ \\
\hline 6. & Трамадол & $\begin{array}{l}\text { Капсулы } 50 \text { мг } \\
\text { Таблетки 50, } 100 \\
\text { Таблетки с пролонгированным высвобождением (пролонгированного } \\
\text { действия), покрытые пленочной оболочкой 100, 150, } 200 \text { мг } \\
\text { Суппозитории ректальные } 100 \text { мг }^{2}\end{array}$ \\
\hline 7. & Парацетамол + трамадол & Таблетки, покрытые пленочной оболочкой 325 мг + 37,5 мг \\
\hline 8. & Тримеперидин & Таблетки 25 мг ${ }^{3}$ \\
\hline 9. & Фентанил & $\begin{array}{l}\text { Трансдермальная терапевтическая система (пластырь) 12,5 мкг/ч, } \\
25 \text { мкг/ч, } 50 \text { мкг/ч, } 75 \text { мкг/ч, } 100 \text { мкг/ч } \\
\text { Спрей назальный дозированный² } 50 \text { мкг/доза, } 100 \text { мкг/доза, } \\
200 \text { мкг/доза }\end{array}$ \\
\hline
\end{tabular}

1 Согласно действующей инструкции препарат применяется только для терапии острой боли сильной и средней интенсивности (послеоперационная, травматическая, ожоговая, при проведении диагностических прочедур)

2 В настоящее время лекарственная форма не доступна для применения

3 Не рекомендуется для курсового применения в виду риска кумуляции нейротоксического метаболита нормеперидина

Таблица 2. Перечень зарегистрированных в РФ опиоидных анальгетиков в инъекционных лекарственных формах

\begin{tabular}{|l|l|l|l|}
\hline № п/п & $\begin{array}{l}\text { Международное } \\
\text { непатентованное } \\
\text { наименование }\end{array}$ & Лекарственная форма & Примечания \\
\hline 1. & Морфин & $\begin{array}{l}\text { Раствор для инъекций и } \\
\text { раствор для подкожного } \\
\text { введения 10 мг/мл в амп. } \\
\text { по 1 мл }\end{array}$ & Рекомендован $^{*}$ \\
\hline 2. & $\begin{array}{l}\text { Кодеин + морфин + } \\
\text { носкапин + папаверин + } \\
\text { тебаин }\end{array}$ & $\begin{array}{l}\text { Раствор для подкожного } \\
\text { введения в амп. по 1 мл }\end{array}$ & Рекомендован $^{*}$ \\
\hline
\end{tabular}




\begin{tabular}{|c|c|c|c|}
\hline № $\Pi / \Pi$ & $\begin{array}{l}\text { Международное } \\
\text { непатентованное } \\
\text { наименование }\end{array}$ & Лекарственная форма & Примечания \\
\hline 3. & Трамадол & $\begin{array}{l}\text { Раствор для инъекций } \\
50 \text { мг/мл в амп. по } 1 \text { и } 2 \text { мл }\end{array}$ & Только в качестве терапии 2 ступени * \\
\hline 4. & Фентанил & $\begin{array}{l}\text { Раствор для внутривен- } \\
\text { ного и внутримышечного } \\
\text { введения } 50 \text { мкг/мл в амп. } \\
\text { по } 1 \text { и } 2 \text { мл }\end{array}$ & Применяется только в стационарах \\
\hline 5. & Бупренорфин & $\begin{array}{l}\text { Раствор для инъекций } \\
0,3 \text { мг/мл в амп. и шприц- } \\
\text { тюбиках по } 1 \text { мл }\end{array}$ & $\begin{array}{l}\text { Как парциальный агонист опиоидных } \\
\text { рецепторов может вызвать синдром от- } \\
\text { мены у пациента, получающего высокие } \\
\text { дозы чистого агониста }\end{array}$ \\
\hline 6. & Тримеперидин & $\begin{array}{l}\text { Раствор для инъекций } \\
10 \text { мг/мл в амп. по } 1 \text { мл }\end{array}$ & $\begin{array}{l}\text { Не рекомендовано курсовое приме- } \\
\text { нение (кумуляция нейротоксического } \\
\text { метаболита) }\end{array}$ \\
\hline 7. & Налбуфин & $\begin{array}{l}\text { Раствор для инъекций } \\
\text { и раствор для внутривен- } \\
\text { ного и внутримышечного } \\
\text { введения } 10 \text { мг/мл, } \\
20 \text { мг/мл в амп. по } 1 \text { мл }\end{array}$ & \multirow{2}{*}{$\begin{array}{l}\text { Не рекомендованы как смешанные } \\
\text { агонисты-антагонисты опиоидных } \\
\text { рецепторов. Не следует комбинировать } \\
\text { с чистыми агонистами в виду риска } \\
\text { провокации синдрома отмены и про- } \\
\text { рыва боли. Могут быть эффективны при } \\
\text { опиоид-индуцированном зуде. }\end{array}$} \\
\hline 8. & Буторфанол & $\begin{array}{l}\text { Раствор для внутривен- } \\
\text { ного и внутримышечного } \\
\text { введения } 2 \text { мг/мл в амп. } \\
\text { по } 1 \text { мл }\end{array}$ & \\
\hline
\end{tabular}

* При невозможности/нецелесообразности применения опиоидов в неинвазивных лекарственных формах

\subsection{1. Лечение боли слабой интенсивности}

Для лечения боли слабой интенсивности используются неопиоидные анальгетики. Данная группа препаратов представлена «чистыми» анальгетиками (парацетамол, метамизол) и НПВП (ацетилсалициловая кислота, диклофенак, кеторолак, кетопрофен, лорноксикам, нимесулид, мелоксикам, целекоксиб и т. д.), ингибирующими циклооксигеназы и образование простагландинов в ЦНС и периферических тканях. Ненаркотические анальгетики парацетамол и метамизол, а также кеторолак оказывают практически исключительно центральное анальгетическое действие и не обладают клинически значимым противовоспалительным эффектом. В свою очередь, НПВП за счет периферического компонента действия уменьшают перифокальное воспаление, отек и сдавление тканей. НПВП являются ко-анальгетиками и препаратами выбора в терапии костно-мышечной боли, в т. ч. связанной с метастазами.

Прием НПВП возможен в течение длительного времени при условии оценки риска развития нежелательных явлений, их профилактики и мониторинга. Недопустимо превышение максимальной суточной дозы препаратов, указанной в инструкции по применению, в частности: парацетамола - 4,0 г; ибупрофена 1200 мг; лорноксикама - 16 мг; мелоксикама - 15 мг; диклофенака - 150 мг; целекоксиба - 400 мг. 
Продолжительность непрерывного применения метамизола и кеторолака рекомендуется ограничивать 5 днями или использовать интермиттирующие курсы. Максимальная суточная доза метамизола при пероральном приеме - 4,0 г; инъекционно - 2,0 г (в 2-3 приема). Максимальная суточная доза кеторолака при приеме внутрь - 40 мг; при инъекционном введении -90 мг в несколько приемов. Традиционную максимальную суточную дозу парацетамола (4,0 г) у пожилых и ослабленных пациентов рекомендуется снижать до 3,0 г в целях снижения риска гепатотоксического действия препарата.

При необходимости анальгетики первой ступени дополняются средствами адъювантной и симптоматической терапии (рис. 4).

\begin{tabular}{|c|c|}
\hline $\begin{array}{l}\text { БОЛЬ < } 40 \% \text { ПО ВАШ } \\
\text { Соматическая: } \\
\text { кожа, мягкие ткани, кости, } \\
\text { лимфатические узлы и др. }\end{array}$ & $\begin{array}{l}\text { - Парацетамол (в т.Ч. в комбинациях) } \\
\text { - или НПВП } \\
\text { - или метамизол натрия/кеторолак короткими курсами } \\
\pm \text { Адъюванты }\end{array}$ \\
\hline Висцеральная: & \\
\hline $\begin{array}{l}\text { перерастяжение капсулы паренхиматозных } \\
\text { органов, стенок полых органов, сдавление } \\
\text { органов средостения } \\
\text { и др. }\end{array}$ & $\begin{array}{l}\text { Адъювантные и симптоматические средства: } \\
\text { - Антиконвульсанты } \\
\text { - Антидепрессанты } \\
\text { - Анксиолитики } \\
\text { - Антигистаминные } \\
\text { - Местные анестетики } \\
\text { - Миорелаксанты центрального действия } \\
\text { - Спазмолитики } \\
\text { - Слабительные, противорвотные, снотворные и др. }\end{array}$ \\
\hline
\end{tabular}

Рисунок 4. Алгоритм терапии ХБС слабой интенсивности.

\subsection{2. Лечение боли умеренной интенсивности}

При болях умеренной интенсивности или непереносимости ненаркотических анальгетиков/ НПВП применяются слабые опиоиды или малые дозы сильных опиоидов.

Из препаратов слабых опиоидов в РФ доступен только трамадол, в т. ч. в форме фиксированной комбинации с парацетамолом. Трамадол является пролекарством. Вариабельность ответа на стартовую дозу трамадола может быть обусловлена различиями в скорости метаболизма, состоянием печени и одновременным приемом лекарственных препаратов, модифицирующих активность цитохромов. Изомеры активных метаболитов трамадола обладают различным механизмом действия - опиоидным и неопиоидным, связанным с ингибированием обратного захвата норадреналина и серотонина. Последнее обусловливает наличие дополнительных лекарственных взаимодействий трамадола с серотонинергическими средствами (антидепрессантами, антиэметиками), а также нежелательных явлений (стимуляции ЦНС, серотонинового синдрома).

Максимальная суточная доза трамадола составляет 400 мг («потолок аналгезии»). Превышение этой дозы приводит к незначительному увеличению обезболивающего эффекта, но повышает риск развития нежелательных яв- 
лений. У пожилых и ослабленных пациентов не рекомендуется превышать суточную дозу трамадола 300 мг.

Согласно рекомендациям Европейской ассоциации паллиативной помощи (ЕАПП/ЕАРС, 2012), в качестве альтернативы «слабым» опиоидам для терапии умеренной боли можно использовать «сильные» опиоиды в низких дозах. Применительно к зарегистрированным в РФ препаратам на второй ступени терапии могут использоваться: морфин перорально в дозе до 30 мг /сут, оксикодон (в составе таблеток пролонгированного действия оксикодон/налоксон) до 20 мг / сут, фентанил в форме ТТС в дозировке 12,5 мкг/ч (на 72 ч), тапентадол перорально - до 200 мг / сут. Пропионилфенилэтоксиэтилпиперидин в форме защечных таблеток, эффект которого развивается в течение 5-10 мин и продолжается 3-4 ч, может применяться для терапии умеренной боли в качестве альтернативного препарата в суточной дозе до 120 мг. Однако его наиболее целесообразно использовать для терапии прорывов боли.

Применение тримеперидина для длительной терапии хронической боли недопустимо, поскольку его метаболит нормеперидин нейротоксичен и обладает способностью к кумуляции (при недостаточной элиминации он способен вызывать тяжелые психозы и судороги).

Для усиления эффекта основных анальгетиков второй ступени по показаниям (для терапии нейропатической боли, спастических состояний и пр.) назначаются адъювантные и симптоматические средства (рис. 5).

Доказательные данные: для терапии онкологической боли умеренной интенсивности показано назначение слабых опиоидов или сильных опиоидов в малых дозах, в т. ч. в комбинации с ненаркотическими анальгетиками/НПВП.

\section{БОЛЬ 40-70\% ПО ВАШ}

\section{Соматическая:}

кожа, мягкие ткани, кости,

лимфатические узлы и др.

Висцеральная:

перерастяжение капсулы

паренхиматозных органов,

органов средостения

и др. стенок полых органов, сдавление

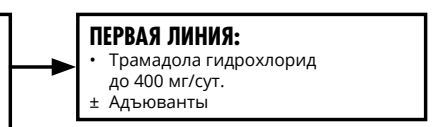

Адъювантные и симптоматические средства:

- Неопиоидные анальгетики, НПВП

- Антиконвульсанты, антидепрессанты, анксиолитики

- Антигистаминные

- Местные анестетики

- Миорелаксанты центрального действия

- Спазмолитики

- Слабительные, противорвотные, снотворные и др.

\section{ВТОРАЯ ЛИНИЯ:}

- Морфина сульфат (таблетки/

капсулы ретард) до 30 мг/сут

- Оксикодон (таблетки ретард

с налоксоном) до 20 мг/сут.

- Фентанил ТТС 12,5 мкг/4

- Бупренорфин ТTС 35 мкг/

\pm Адъюванты

Рисунок 5. Алгоритм терапии ХБС умеренной интенсивности. 


\subsection{3. Лечение боли сильной интенсивности}

Боль сильной интенсивности требует применения сильных опиоидных анальгетиков.

Морфин - наиболее широко применяемый препарат для терапии ХБС онкологического генеза. Могут использоваться пероральные формы морфина с немедленным (таблетки, раствор для приема внутрь) или модифицированным (таблетки и капсулы) высвобождением. Продолжительность действия морфина в пероральных формах с немедленным высвобождением составляет 4-6 ч (аналогично инъекциям), в пролонгированных формах - 10-12 ч. Препараты морфина короткого действия наиболее удобны для титрования дозы и терапии прорывов боли. Пролонгированные формы, назначаемые дважды в сутки, наиболее удобны для контроля постоянной боли. Максимальной дозы морфина у опиоид-толерантных пациентов не существует. Каждому пациенту доза препарата титруется до наименьшей эффективной и удовлетворительно переносимой.

Фиксированная комбинация оксикодон/налоксон в форме таблеток продленного действия назначается дважды в сутки. Обезболивающее действие развивается за счет оксикодона, имеющего высокую биодоступность при пероральном приеме (около $85 \%$ ). Налоксон, обладающий низкой биодоступностью при приеме внутрь (около $3 \%$ ), действует как антагонист опиатных рецепторов ЖКТ и уменьшает выраженность обстипационного эффекта оксикодона. Максимальная суточная доза таблеток оксикодон/налоксон составляет 160/80 мг.

Пропионилфенилэтоксиэтилпиперидин в форме защечных таблеток, обеспечивающих быстрый, но непродолжительный эффект, требует частого приема. При регулярном приеме в высоких дозах значительно повышается его наркогенный потенциал. Это ограничивает применение пропионилфенилэтоксиэтилпиперидина в качестве препарата для постоянной терапии сильного ХБС. Максимальная суточная доза препарата составляет 250 мг.

Фентанил в форме ТТС (пластыря) наиболее подходит пациентам со стабильной потребностью в опиоидах (т. е. опиоид-толерантным). Является терапией выбора у пациентов с нарушением глотания; обструкцией ЖКТ; плохой переносимостью морфина; плохой переносимостью пероральной терапии морфином или другими опиоидами. Кроме того, в виду метаболизма фентанила до неактивных продуктов, препарат подходит для терапии сильного ХБС у пациента с нарушением функции почек, в т. ч. с хронической болезнью почек 4 и 5 стадий (СКФ < 30 мл / мин).

Относительный риск развития нежелательных явлений со стороны ЖКТ (тошноты, рвоты, запора), задержки мочи и сонливости при применении ТТС фентанила на 30-60\% ниже, чем при использовании пероральных форм морфина [57].

Обезболивающий эффект трансдермальных опиоидов развивается постепенно, поэтому при первом применении ТТС в течение первых суток необходимо сохранять прежнюю обезболивающую терапию. Начальную оценку 
максимального обезболивающего эффекта ТТС опиоида следует проводить не ранее чем через 24 ч после аппликации, а окончательную - после достижения стационарной концентрации опиоида в крови (2 последовательные аппликации пластыря).

Требуется соблюдать осторожность при применении ТТС у пациентов с кахексией и лихорадкой. Нельзя подвергать пластырь действию внешних источников тепла (грелки, одеяла с подогревом, сауна и пр.), т. к. скорость высвобождения фентанила из системы может увеличиться, и возникнет угроза передозировки.

Продолжительность действия ТТС фентанила составляет 3 суток. Поскольку фентанил является чистым агонистом $\mu$-опиатных рецепторов, он не имеет максимальной суточной дозы у опиоид-толерантных пациентов.

Тапентадол имеет двойной механизм действия - опиоидный и неопиоидный (норадренергический). В определенной степени фармакологически напоминает трамадол, однако, в отличие от последнего, имеет более высокий анальгетический потенциал (слабее перорального морфина примерно в 2,5 раза), является активным лекарством (эффект не зависит от полиморфизма цитохромов печени), не влияет на обратный захват серотонина (меньший риск лекарственных взаимодействий), метаболизируется, преимущественно до неактивных метаболитов путем глюкуронизации (низкий риск кумуляции при умеренных нарушениях функции почек). Дополнительный норадренергический механизм действия тапентадола позволяет в определенной мере воздействовать на нейропатический компонент боли.

Нейропатическая боль обычно резистентна к терапии опиоидами даже высокой потенции. В случае наличия у пациента нейропатического компонента ХБС более целесообразно не эскалировать дозу основного анальгетика, а дополнять схему терапии адъювантными препаратами (рис. 6). Помимо этого, на данном этапе терапии ХБС используются симптоматические средства, необходимые в т. ч. для купирования нежелательных эффектов опиоидов (см. далее).

Доказательные данные: препаратом первого выбора для терапии онкологической боли сильной интенсивности является оральный морфин, во всех случаях, когда возможен пероральный прием препарата. В качестве альтернативы можно использовать препараты других сильных опиоидов, предпочтительно в неинвазивных формах.

У пациентов с нарушением глотания, тошнотой и рвотой, а также в конце жизни, у немощных больных и иных случаях, когда продолжение приема препаратов в пероральных лекарственных формах невозможно, может потребоваться инъекционное введение опиоидов. В ряде случаев используется существующий венозный доступ (порт), в большинстве других - подкожное введение. Эффективность, переносимость и доза опиоида при внутривенном и подкожном введении одинаковы, однако внутривенный путь отличается более быстрой скоростью наступления обезболивающего эффекта.

Доказательные данные: при невозможности применения опиоидов в пероральных или трансдермальной формах подкожное введение опиоида (морфи- 
на) является альтернативой первого выбора. Внутривенное введение опиоида следует использовать при наличии противопоказаний к подкожному введению (отеки, нарушения микроциркуляции, расстройства гемостаза, необходимость введения большой дозы или объема раствора препарата).

Болеутоляющий эффект опиоидных анальгетиков реализуется через воздействие на опиатные рецепторы. Они расположены в ЦНС и являются также точками приложения эндорфинов - собственных опиоидных пептидов, выработка которых в случае продолжительных интенсивных болей недостаточна. Резкая отмена или пропуск очередной дозы длительно применяющегося опиоида (особенно, в высокой дозе) или применение антагониста (парциального агониста) опиоидных рецепторов, может спровоцировать синдром отмены с возникновением прорыва боли.

\begin{tabular}{|c|c|}
\hline $\begin{array}{l}\text { БОЛЬ > 70\% ПО ВАШ } \\
\text { Соматическая: } \\
\text { кожа, мягкие ткани, кости, лимфатиче- } \\
\text { ские узлы и др. } \\
\text { Висцеральная: } \\
\text { перерастяжение капсулы паренхима- } \\
\text { тозных органов, стенок полых органов, } \\
\text { сдавление органов средостения и др. }\end{array}$ & $\begin{array}{l}\text { ОСНОВНАЯ ТЕРАПИЯ } \\
\text { - Морфина сульфат (таблетки/ } \\
\text { капсулы ретард) более } 30 \text { мг/сут. } \\
\text { - Оксикодон (таблетки ретард } \\
\text { с налоксоном) 30-80 мг/сут. } \\
\text { - Фентанил ТТС от } 25 \text { мкг/4 } \\
\text { - Бупренорфин ТТС от 52,5 мкг/4 } \\
\pm \text { Адъюванты }\end{array}$ \\
\hline
\end{tabular}

\section{ТЕРАПИЯ ПРОРЫВОВ БОЛИ}

- Морфина гидрохлорид (1\% р-р в амп.)

- Пропионил-фенилэтоксиэтилпиперидин (таблетки защечные)

\footnotetext{
Адъювантные и симптоматические средства:

- Неопиоидные анальгетики, НПВП

- Антиконвульсанты, антидепрессанты, анксиолитики

- Антигистаминные

- Местные анестетики

- Миорелаксанты центрального действия

- Спазмолитики

- Слабительные, противорвотные, снотворные и др.
}

Рисунок 6. Алгоритм терапии ХБС сильной интенсивности.

\subsection{4. Принципы титрования дозы опиоидов}

Наиболее безопасным методом подбора суточной дозы сильного опиоида является назначение пероральных форм морфина короткого действия по 5 мг каждые 4 ч, при необходимости дополняя их приемом 5 мг того же препарата между основными дозами (вплоть до ежечасного) (II, B). В настоящее время для этой цели можно использовать таблетки морфина, покрытые пленочной оболочкой, в дозировке 5 мг либо раствор морфина для приема внутрь 2 мг/1 мл в амп по 5 мл (0,5 мл препарата). С целью титрования дозы опиоида допустимо использовать малые дозировки перорального морфина в формах с модифицированным высвобождением вещества (10 мг дважды в сутки), также дополняя их морфином быстрого действия по потребности для купирования прорывов боли.

Инъекционный морфин также можно использовать для определения суточной дозы опиоида. В этом случае раствор морфина 1 мг/мл вводится подкожно каждые 4 ч в дозе 5 мг (0,5 мл раствора) и при необходимости дополнительно 5 мг того 
же препарата используется для купирования прорывов боли между основными инъекциями (вплоть до ежечасного введения). У пациентов с очень сильной болью рекомендуется внутривенное титрование дозы морфина (например, по 1,5 мг каждые 10 мин) для быстрого достижения обезболивания (III, B).

После титрования и определения суточной дозы морфина (включающей то количество препарата, которое потребовалось для купирования прорывов боли), целесообразно перейти на опиоид с модифицированным высвобождением вещества (пролонгированного действия) для контроля постоянной боли в течение суток.

В дальнейшем подобранную дозу можно корректировать, увеличивая ее не более чем на $30 \%$ за сутки при недостаточной эффективности, или же уменьшать дозу опиоида в случае плохой переносимости при условии сохранения адекватного обезболивания (II, A).

Перевод пациента с парентерального или перорального морфина на другой опиоид, в том числе, в рамках ротации опиоидов в связи с недостаточной эффективностью и/или плохой переносимостью, осуществляется на основании таблиц эквипотенциальных (эквианальгетических) доз, приводимых в инструкции по медицинскому применению соответствующего препарата.

\subsection{5. Принципы терапии прорывной раковой боли}

Прорывная раковая боль - это транзиторное усиление боли, возникающее на фоне относительно стабильной и адекватно контролируемой опиоидом основной боли. Скорость развития эпизода прорывной раковой боли колеблется от 30 секунд до 10 минут. Средняя продолжительность эпизода - около 30 минут. Для терапии прорывной боли используются опиоиды с быстрым наступлением и короткой продолжительностью эффекта, например, пероральный морфин в таблетках или растворах. Подкожное введение морфина отличается более быстрым наступлением эффекта, однако менее предпочтительно ввиду инвазивности. Доза морфина для купирования прорывной раковой боли обычно эквивалентна 10-15\% суточной дозы опиоида (II, A).

Пропионилфенилэтоксиэтилпиперидин может использоваться для терапии прорывов боли в дозе от 10 до 20-40 мг в таблетках защечно или под язык.

За рубежом для купирования прорывной боли также применяются трансмукозальные формы фентанила с немедленным высвобождением вещества (интраназальный спрей, сублингвальные таблетки, «леденцы»и т. д.). Они отличаются наибольшей скоростью развития эффекта среди всех неинвазивных форм опиоидов. В РФ зарегистрирован спрей назальный дозированный фентанила в 3 дозировках: 50 мкг, 100 мкг и 200 мкг/доза. Однако до настоящего времени препарат недоступен для применения на практике.

Если в течение суток пациенту требуется более 4 доз опиоида для купирования прорывов боли, необходимо скорректировать суточную дозу основного опиоида продленного действия, а также рассмотреть вопрос о целесообразности назначения адъювантных средств. 


\subsection{6. Адъювантные средства в терапии ХБС}

К адъювантным средствам относятся антиконвульсанты, антидепрессанты, спазмолитики, анксиолитики, антигистаминные средства, глюкокортикостероиды, местные анестетики и др. Включение адъювантных средств в схему терапии ХБС позволяет усилить эффект основного анальгетика и ограничить эскалацию его дозы, что в итоге способствует уменьшению нежелательных явлений и повышению качества жизни пациента. Адъювантные средства из класса антиконвульсантов, антидепрессантов и местных анестетиков незаменимы в терапии нейропатического компонента ХБС. Наиболее часто используются следующие препараты:

- Габапентин 300-3600 мг/сут;

- Прегабалин 150-600 мг/сут;

- Карбамазепин 400-600 мг/сут;

- Амитриптилин 25-75 мг/сут;

- Венлафаксин 70-225 мг/сут;

- Дулоксетин 60-120 мг/сут;

- Лидокаин в форме ТТС 1-3 пластыря на 12 часов с последующим 12-часовым перерывом при локальных невропатиях с преобладанием болевых расстройств кожной чувствительности (аллодиния, гипералгезия).

При нейропатической боли вследствие костных метастазов необходимо рассмотреть целесообразность лучевой терапии.

\section{4. Особенности обезболивания в последние часы жизни $[3,34,49,50]$}

Не рекомендуется снижать дозу опиоида при наличии артериальной гипотензии или спутанности сознания (если они не являются следствием избыточной дозы опиоида).

В случае отмены опиоидного анальгетика его дозу следует снижать постепенно, не более, чем на $1 \frac{1}{2}$ за сутки во избежание синдрома отмены и прорыва боли.

Рекомендуется сохранять прием опиоидов в эффективной дозе даже при отсутствии сознания.

Рекомендуется оценивать выраженность и динамику других тягостных симптомов (пролежни, рвота, отеки, запоры, задержка мочи, эпизоды возбуждения), усиливающих страдания пациента.

При рефрактерном болевом синдроме целесообразно рассмотреть вопрос о проведении медикаментозной седации с помощью нейролептиков, бензодиазепинов, барбитуратов и пропофола. Возможность медикаментозной седации обсуждается с пациентом и/или его законным представителем и рассматривается на заседании врачебной комиссии. 


\section{5. ПРИНЦИПЫ ПРОФИЛАКТИКИ И ТЕРАПИИ НЕЖЕЛАТЕЛЬНЫХ ЯВЛЕНИЙ ОБЕЗБОЛИВАЮЩЕЙ ТЕРАПИИ}

\section{1. Нежелательные явления неопиоидных анальгетиков}

При назначении ненаркотических анальгетиков следует помнить о противопоказаниях и ограничениях к их применению. Специфические побочные эффекты, дозы ненаркотических анальгетиков разных групп, их возможное взаимодействие между собой необходимо учитывать у онкологических больных, особенно у ослабленных и пожилых пациентов после проведения курсов химио-и лучевой терапии.

Суточная доза парацетамола у пациентов с хроническими и декомпенсированными заболеваниями печени, хроническим алкоголизмом, кахексией и дегидратацией не должна превышать 3,0 г. Пациентам с множественным метастатическим поражением печени и явлениями печеночной недостаточности следует избегать назначения парацетамола. Метамизол противопоказан пациентам с лейкопенией в виду риска гематотоксического действия. Максимальная суточная доза кеторолака у пациентов старше 65 лет или с нарушенной функцией почек не должна превышать 60 мг. Курсовой прием метамизола и кеторолака следует ограничивать 5 днями.

Все НПВП противопоказаны пациентам с эрозивно-язвенными заболеваниями ЖКТ в стадии обострения, выраженной печеночной или почечной недостаточностью, «аспириновой триадой», заболеваниями сердечно-сосудистой системы (XCH II-IV функционального класса по классификации NYHA, ИБC, неконтролируемая АГ, заболевания периферических артерий, цереброваскулярные заболевания) вследствие риска тромбообразования, инфаркта миокарда и тромбоэмболических осложнений. Селективные ингибиторы ЦОГ-2 (коксибы) могут быть предпочтительнее традиционным НПВП у пациентов высокого риска по развитию осложнений со стороны верхних отделов ЖКТ, т. е. при наличии в анамнезе язвы, кровотечения или перфорации ЖКТ, а также при приеме любых антиагрегантов и/или антикоагулянтов. Дополнительным методом профилактики НПВП-гастропатий, целесообразным в т. ч. при назначении коксибов пациентам высокого риска, является прием ингибиторов протонной помпы.

\section{2. Нежелательные явления опиоидных анальгетиков}

К наиболее частым нежелательным явлениям опиоидных анальгетиков относятся тошнота и рвота, запоры, седация. Тошноту и рвоту можно купировать метоклопрамидом или препаратами нейролептиков. Терапия запоров предполагает применение слабительных осмотического (лактулоза, макрогол) или стимулирующего (бисакодил, препараты сенны, натрия пикосульфат и пр.) типов действия. Седативный эффект опиоидов корригируется уменьшением дозировки препарата, если это возможно, или заменой опиоида. Наиболее опасной нежелательной реакцией является угнетение дыхания, возникаю- 
щее при передозировке опиоида и устраняемое внутривенным введением налоксона. Необходимо учитывать короткую продолжительность действия налоксона и необходимость повторного введения препарата через 40-60 мин при возобновлении симптомов респираторной депрессии.

При применении трамадола возможно развитие дополнительных неопиоидных побочных эффектов. Они обусловлены серотониномиметическим стимулирующим действием на ЦНС. Может отмечаться эйфоризирующий эффект, ажитация, лабильность психики, галлюцинации, нарушения сна, судороги и пр. Потенциально жизнеугрожающим состоянием является серотониновый синдром. Риск его развития повышается при одновременном приеме трамадола с другими серотонинергическими препаратами: антидепрессантами (селективными ингибиторами обратного захвата серотонина, ингибиторами обратного захвата серотонина и норадреналина, трициклическими антидепрессантами, ингибиторами моноаминоаксидазы, миртазапином), противомигренозными агонистами 5-HТ, -серотониновых рецепторов (триптанами), антиэметиками блокаторами 5- $\mathrm{HT}_{3}$-серотониновых рецепторов (сетронами). Серотониновый синдром развивается обычно в течение нескольких часов или дней от начала совместного приема трамадола с вышеуказанными препаратами. Специфическим антидотом является ципрогептадин.

Следует подчеркнуть, что до настоящего времени не имеется доказательств меньшего риска развития психической зависимости от «слабых» опиоидов в сравнении с «сильными» в эквианальгетических дозах.

Инъекционные опиоиды в силу кратковременности эффекта требуют частого применения, болезненны, характеризуются более быстрым развитием толерантности и лекарственной зависимости, нарушают сон и дневную активность пациента, сопряжены с риском вторичной инфекции у ослабленных больных, требуют участия медицинского персонала. По этой причине инъекционные формы опиоидов для терапии ХБС должны применяться лишь в исключительных случаях при невозможности использования неинвазивных лекарственных форм (II, B)

\section{6. ХРАНЕНИЕ}

Лекарственные препараты в домашних условиях необходимо хранить в местах, недоступных для детей.

Недопустима передача лекарственных препаратов другим людям.

Согласно Федеральному закону РФ от 31.12.2014 № 501-ФЗ запрещается требовать от пациентов и их родственников «возврат первичных упаковок и вторичных (потребительских) упаковок использованных в медицинских целях наркотических лекарственных препаратов и психотропных лекарственных препаратов, в том числе в форме трансдермальных терапевтических систем, содержащих наркотические средства, при выписке новых рецептов на лекарственные препараты, содержащие назначение наркотических лекарственных препаратов и психотропных лекарственных препаратов». 